\title{
A New Option for Therapeutic Management of Patients with Cerebrovascular Disease
}

\section{A Closer Look at the PRoFESS Trial}

\author{
Massimo Volpe $e^{1,2}$ \\ 1 Division of Cardiology, II Faculty of Medicine, University of Rome "La Sapienza", Sant'Andrea Hospital, Rome, Italy \\ 2 IRCCS Neuromed, Pozzilli (IS), Isernia, Italy
}

\begin{abstract}
Stroke represents the most devastating cardiovascular (CV) disease in Western countries, accounting for approximately 700000 cases per year, including 500000 first attacks and 200000 recurrent episodes. High blood pressure is the most relevant, modifiable risk factor for developing stroke. Available evidence demonstrates that in hypertensive patients, especially those with additional CV risk factors, organ damage, diabetes mellitus or other clinical conditions, even small decreases in blood pressure levels are associated with large reductions in the incidence of cerebrovascular events, mostly stroke, in a setting of primary prevention. The benefits of blood pressure reductions, however, are not strictly proportional to stroke incidence, and it has been postulated that the different classes of antihypertensive drugs may have specific properties for organ protection and cerebrovascular prevention. In particular, the hypothesis of a higher cerebrovascular protection provided by newer antihypertensive agents with respect to the conventional antihypertensive therapy is an attractive perspective, both in primary and secondary prevention.
\end{abstract}

Received for publication 4 June 2008; accepted for publication 24 July 2008.

Key words: hypertension, stroke, ACE inhibitors, angiotensin II receptor blockers, cardiovascular risk.

\section{Antihypertensive Therapy and Cerebrovascular Risk}

As a major cause of morbidity and mortality, ischaemic stroke currently represents the third most common cause of death in developed countries after coronary artery disease and cancer, and it is expected to dramatically increase over the next 2 decades. ${ }^{[1]}$ The risk of a recurrent stroke or transient ischaemic attack (TIA) ranges between $5 \%$ and $15 \%$ per year in the general population, and it increases progressively with age and following a first ischaemic episode. ${ }^{[2,3]}$

Effective prevention of recurrent stroke still represents a major challenge for physicians. ${ }^{[4]}$ Recent surveys have documented that physicians considered stroke prevention as the most important outcome in the clinical management of hypertensive patients, both at the general practitioner ${ }^{[5]}$ and at the cardiologist level. ${ }^{[6]}$ In this setting, the use of low-dose aspirin (acetylsalicylic acid) is supported by a number of clinical studies and is consistently recommended by international guidelines. ${ }^{[7]}$ On the other hand, while effective and tight blood pressure (BP) control is primarily recommended for reducing stroke risk in both primary and secondary prevention, ${ }^{[8]}$ it is still unclear whether specific drug classes should be preferred.

Among effective antihypertensive strategies, ACE inhibition is reported to decrease stroke recurrence. In the PROGRESS (Perindopril Protection Against Recurrent Stroke) trial, for example, use of an ACE inhibitor-based therapy reduced stroke recurrence by $28 \%$ versus placebo. ${ }^{[9]}$ This beneficial effect, however, achieved statistical significance only when the diuretic indapamide was given in combination with perindopril, whereas perindopril alone had practically no effect on stroke recurrence. ${ }^{\text {9] }}$ In addition, the benefits, when presented, were associated with significant BP reductions compared with placebo. ${ }^{[9]}$ Similarly, in the high-risk population of the HOPE (Health Outcomes Prevention Evaluation) study, ${ }^{[10]}$ an antihypertensive strategy based on the ACE inhibitor ramipril significantly reduced cerebrovascular events compared with placebo. Whether the observed larger BP reduction by the ACE inhibitor played a determinant role is still debated.

In this view, it has been postulated that the use of a more selective blockade of the renin-angiotensin system (RAS), such as that provided by angiotensin II type 1 receptor antagonists (angio- 
Table I. Blood pressure (BP) difference between telmisartan and placebo over time

\begin{tabular}{lll}
\hline Time & Systolic BP $(\mathrm{mmHg})$ & Diastolic BP $(\mathrm{mmHg})$ \\
\hline $1 \mathrm{mo}$ & -5.4 & -2.8 \\
$6 \mathrm{mo}$ & -4.5 & -2.3 \\
$1 \mathrm{y}$ & -4.1 & -2.1 \\
$2 \mathrm{y}$ & -3.6 & -1.7 \\
3 y & -3.1 & -1.3 \\
Average difference & -3.8 & -2.0 \\
\hline
\end{tabular}

tensin receptor blockers [ARBs])-based therapy, may confer specific benefits in terms of stroke prevention, even for similar BP lowering efficacy. This hypothesis has been supported by the results of the LIFE (Losartan Intervention For End-point reduction in hypertension) trial ${ }^{[11]}$ for primary prevention of stroke in hypertensive patients with electrocardiographic evidence of left ventricular hypertrophy and, more recently, by the MOSES (Morbidity and Mortality After Stroke, Eprosartan Compared With Nitrendipine for Secondary Prevention) study in patients with previous stroke. ${ }^{[12]}$ This latter study has demonstrated that while the ARB eprosartan produced similar BP reductions to the dihydropiridinic calcium channel blocker (CCB) nitrendipine, the primary endpoint (e.g. recurrent cerebrovascular events) was significantly lower in the ARB-based arm than in the CCB-based arm.

\section{Recent Findings of the PROFESS Study}

On the basis of these considerations, the PRoFESS (Prevention Regimen for Effectively Avoiding Second Strokes) trial was designed to expand this hypothesis in a $2 \times 2$ factorial, comparing the combination of aspirin/extended-release dipyridamole to clopidogrel and the effect of adding the ARB telmisartan to conventional treatment for reducing the risk of subsequent stroke. ${ }^{[13]}$ Patients were 50 years or older and had to have had an ischaemic stroke within the past 120 days. The primary endpoint was time to first recurrent stroke of any type over the course of the study, and the primary hypothesis of PRoFESS was that the ARB telmisartan would be superior to placebo in reducing recurrent stroke and, secondly, that telmisartan was superior than placebo in reducing the composite outcome of recurrent stroke, myocardial infarction, vascular death, or new or worsening heart failure.

In this large-scale, international, randomized trial involving 695 sites in 35 countries, 20332 patients were randomized to telmisartan $(n=10146)$ or placebo $(n=10186)$ and followed for 3.5 years. In addition to study medications, anywhere from $20 \%$ to $35 \%$ of patients also were taking BP lowering drugs, including diuretics, ACE inhibitors, $\beta$-blockers, or CCBs, during the trial. At all timepoints measured, telmisartan produced a reduction in both systolic and diastolic BP levels versus placebo (table I). Although the primary endpoint of recurrent stroke was reduced in the telmisartan group, the overall effect was not significantly different from placebo ( $8.7 \%$ vs $9.2 \% ; \mathrm{p}=0.231$ ) [figure 1]. In particular, more patients in the telmisartan group experienced recurrent strokes in the first 6 months of the study (347 vs 326), but after that timepoint, the placebo group had more strokes out to the end of the study (533 vs 608), which was significant for the interaction ( $\mathrm{p}=$ 0.042).

Although the reasons for these divergent trends cannot be clarified at this moment, it is likely that the large BP reduction observed in the telmisartan group as compared to placebo (table I) may have played a detrimental role in high-risk patients experiencing a recent stroke. Treatment could have, in fact, been started immediately after stroke. On the other hand, given the lesser number of stroke recurrences in the telmisartan arm in the last 3 years of the study, it is reasonable to speculate that a longer observation (e.g. 5 years) would have led to a significant difference between the two Kaplan-Meier curves. Other hypotheses cannot be excluded: for example, that angiotensin II could play a protective role in the ischaemic area of the brain in the acute phase of stroke, ${ }^{[14]}$ or that stimulation of angiotensin II subtype 2 (AT2) receptors by unbound angiotensin II may antagonize new angiogenesis in the ischaemic or penumbra area. ${ }^{[15]}$ In these latter two hypotheses, obviously selective blockade of the AT1 subtype receptors on the top of conventional therapy would not help. On the other hand, it should be tested by the design of the study, especially if one considers the very high proportion of patients in the two arms already receiving a blockade of the RAS by ACE inhibition (28.4\% vs $33.9 \%)$.

The placebo group also experienced more secondary outcome events, including stroke, MI, vascular death and heart failure (table II). However, the difference was only significant for the interaction with regards to time, which paralleled the primary outcome

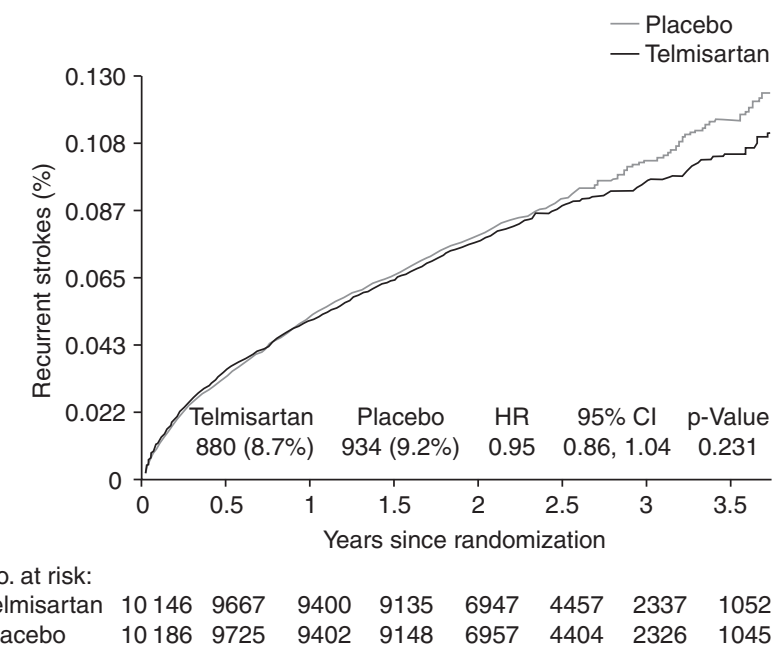

Fig. 1. Primary outcome: recurrent stroke. $\mathbf{H R}=$ hazard ratio. 
Table II. Hazard ratio for recurrent stroke by time between telmisartan and placebo

\begin{tabular}{lllll}
\hline $\begin{array}{l}\text { No. of } \\
\text { strokes }\end{array}$ & $\begin{array}{l}\text { Telmisartan } \\
(\mathrm{n}=10146)\end{array}$ & $\begin{array}{l}\text { Placebo } \\
(\mathrm{n}=10186)\end{array}$ & Difference & $\begin{array}{l}\text { Hazard ratio } \\
(95 \% \mathrm{Cl})\end{array}$ \\
\hline $0-6 \mathrm{mo}$ & 347 & 326 & +21 & $1.07(0.92,1.25)^{*}$ \\
$>6 \mathrm{mo}$ & 533 & 608 & -75 & $0.88(0.78,0.99)^{*}$ \\
Overall & 880 & 934 & -54 & $0.95(0.86,1.04)$ \\
\hline
\end{tabular}

${ }^{*} p$-Value for interaction $=0.042$.

in that more telmisartan patients had a secondary outcome event in the first 6 months, but the placebo group had more events in the following 3 years $(p=0.004)$. Finally, significantly more patients randomized to receive telmisartan discontinued taking their medication $(\mathrm{p}<0.001)$, primarily due to hypotensive symptoms, as also observed in the ONTARGET (ONgoing Telmisartan Alone and in combination with Ramipril Global Endpoint) study. ${ }^{[16]}$ Altogether, the interesting results of this study re-open the question of whether it is recommended and safe to aggressively lower BP levels in the early stages after an acute stroke.

\section{Conclusion}

Although the use of telmisartan did not prove to be superior to placebo in secondary stroke prevention, the study analysis suggests that a potential later benefit specifically related to the addition of telmisartan to standard best treatment becomes evident over time following stroke. These benefits that begin to appear after 6 months are consistent with those seen in previous clinical trials with $\mathrm{ARBS}^{[11,12]}$ and are supported by recent meta-analy$\operatorname{ses}^{[17,18]}$ focused on the benefits of RAS blocking agents in stroke prevention.

\section{Acknowledgements}

No sources of funding were used to assist in the preparation of this review. The author has no conflicts of interest that are directly relevant to the content of this review.

The author wishes to thank Giuliano Tocci, MD, for assistance in preparing and revising the manuscript.

\section{References}

1. Rosamond W, Flegal K, Furie K, et al. American Heart Association Statistics Committee and Stroke Statistics Subcommittee. Heart disease and stroke statistics - 2008 update: a report from the American Heart Association Statistics Committee and Stroke Statistics Subcommittee. Circulation 2008 Jan 29; 117 (4): e25-146

2. Lovett JK, Coull AJ, Rothwell PM. Early risk of recurrence by subtype of ischemic stroke in population-based incidence studies. Neurology 2004; 62: 569-73

3. Lewington S, Clarke R, Qizilbash N, et al., for the Prospective Studies Collaboration. Age-specific relevance of usual blood pressure to vascular mortality: a meta-analysis of individual data for one million adults in 61 prospective studies. Lancet 2002; 360: 1903-13

4. Volpe M, Tocci G. Antihypertensive therapy and cerebrovascular protection. Curr Opin Nephrol Hypertens 2006; 15 (5): 498-504

5. Volpe M, Machado E. Treatment priorities and current prescribing patterns in hypertension: results of Global Research on Attitudes about hypertension and
Stroke Prevention (GRASP), an international physician survey. Curr Med Res Opin 2004; 20 (7): 1151-60

6. Tocci G, Giovannelli S, Sciarretta S, et al. Management of hypertension and stroke prevention: results of the Italian cardiologist survey. Int J Cardiol Pract. In press

7. Graham I, Atar D, Borch-Johnsen K, et al. European Society of Cardiology (ESC); European Association for Cardiovascular Prevention and Rehabilitation (EACPR); Council on Cardiovascular Nursing; European Association for Study of Diabetes (EASD); International Diabetes Federation Europe (IDF-Europe); European Stroke Initiative (EUSI); Society of Behavioural Medicine (ISBM); European Society of Hypertension (ESH); WONCA Europe (European Society of General Practice/Family Medicine); European Heart Network (EHN); European Atherosclerosis Society (EAS). European guidelines on cardiovascular disease prevention in clinical practice: full text. Fourth Joint Task Force of the European Society of Cardiology and other societies on cardiovascular disease prevention in clinical practice (constituted by representatives of nine societies and by invited experts). Eur J Cardiovasc Prev Rehabil 2007; 14 Suppl. 2: S1-113

8. Mancia G, De Backer G, Dominiczak A, et al. Management of Arterial Hypertension of the European Society of Hypertension; European Society of Cardiology. 2007 Guidelines for the Management of Arterial Hypertension: the Task Force for the Management of Arterial Hypertension of the European Society of Hypertension (ESH) and of the European Society of Cardiology (ESC). J Hypertens 2007; 25 (6): 1105-87

9. PROGRESS Collaborative Group. Randomised trial of a perindopril-based bloodpressure-lowering regimen among 6105 individuals with previous stroke or transient ischemic attack. Lancet 2001; 358: 1033-41

10. Yusuf S, Sleight P, Dagenais G, et al., for the Hearth Outcomes Prevention Evaluation (HOPE) Study Group. Effects of angiotensin-converting enzyme inhibitor, ramipril, on cardiovascular events in high-risk patients. N Engl J Med 2000; 342: $145-53$

11. Dahlof B, Devereux RB, Kjeldsen SE, et al., for the LIFE Study Group. Cardiovascular morbidity and mortality in the Losartan Intervention For End-point reduction in hypertension (LIFE) study: a randomised trial against atenolol. Lancet 2002; 359: 995-1003

12. Schrader J, Lüders S, Kulschewski A, et al. Morbidity and Mortality After Stroke, Eprosartan Compared with Nitrendipine for Secondary Prevention: principal results of a prospective randomized controlled study (MOSES). Stroke 2005; 36: $1218-26$

13. Diener HC, Sacco R, Yusuf S. Steering Committee; PRoFESS Study Group. Rationale, design and baseline data of a randomized, double-blind, controlled trial comparing two antithrombotic regimens (a fixed-dose combination of extended-release dipyridamole plus ASA with clopidogrel) and telmisartan versus placebo in patients with strokes: the Prevention Regimen for Effectively Avoiding Second Strokes Trial (PRoFESS). Cerebrovasc Dis 2007; 23: 368-80

14. Fournier A, Messerli FH, Achard JM, et al. Cerebroprotection mediated by angiotensin II: a hypothesis supported by recent randomized clinical trials. J Am Coll Cardiol 2004 Apr 21; 43 (8): 1343-7

15. Thöne-Reineke C, Steckelings UM, Unger T. Angiotensin receptor blockers and cerebral protection in stroke. J Hypertens Suppl 2006 Mar; 24 (1): S115-21

16. Yusuf S, Teo KK, Pogue J, et al., on behalf of the ONTARGET Investigators. Telmisartan, ramipril, or both in patients at high risk for vascular events: the ONgoing Telmisartan Alone and in combination with Ramipril Global Endpoint (ONTARGET) Trial. N Engl J Med 2008 Apr 10; 358 (15): 1547-59

17. Turnbull F, Neal B, Algert C, et al., for the Blood Pressure Lowering Treatment Trialists' Collaboration. Effects of different blood pressure lowering regimens on major cardiovascular events in individuals with and without diabetes mellitus. Arch Intern Med 2005; 165: 1410-9

18. Reboldi G, Angeli F, Cavallini C, et al. Comparison between angiotensin-converting enzyme inhibitors and angiotensin receptor blockers on the risk of myocardial infarction, stroke and death: a meta-analysis. J Hypertens $2008 \mathrm{Jul}$; 26 (7): 1282-9

Correspondence: Prof. Massimo Volpe, Chair and Division of Cardiology, II Faculty of Medicine, University of Rome "La Sapienza", Sant'Andrea Hospital, Via di Grottarossa, 1035-9, 00189 Rome, Italy.

E-mail: massimo.volpe@uniroma1.it 